\title{
Medios de comunicación y educación: Reflexiones a propósito de la renovación curricular en la República Dominicana
}

\author{
Media and Education: Reflections on the Curricula \\ Reform in the Dominican Republic
}

Fernando García-Leguizamón ${ }^{1}$ ORCID: 0000-0003-4796-7799

Recibido: 28-8-2018 • Aprobado: 27-9-2018

Cómo citar: García-Leguizamón, F. (2018). Medios de comunicación y educación: Reflexiones a propósito de la renovación curricular en la República Dominicana. Ciencia y Educación, 2(2), 29-40. doi: http://dx.doi.org/10.22206/cyed.2018.v2i2.pp29-40

\section{Resumen}

A partir de un diálogo con el documento del Ministerio de Educación de la República Dominicana: Bases de la Revisión y Actualización Curricular (MINERD, 2016), y señalando un conjunto de problemáticas mediáticas contemporáneas que se presentan como desafío al logro de los fines de la educación en una sociedad democrática; este artículo de reflexión pretende mostrar la necesidad y la pertinencia de promover una educación en medios en la escuela.

Palabras clave: Educación en medios, competencias, competencia mediática, educación en República Dominicana

\begin{abstract}
Based on a dialogue with the document of the Ministry of Education of the Dominican Republic: Bases of the Review and Updating of Curriculum (MINERD, 2016), and pointing out a set of contemporary media issues that are presented as a challenge to the achievement of the goals of the Education in a democratic society, this article of reflection aims to show the need and relevance of promoting media education at school.
\end{abstract}

Keywords: Media education, competences, media literacy, education in the Dominican Republic.

1. Instituto Superior de Formación Docente Salomé Ureña (ISFODOSU), República Dominicana, fernando.garcia@isfodosu.edu.do 
Lo que conocemos de la sociedad, del mundo en que vivimos, lo conocemos por los medios de comunicación. Esto vale no solo para nuestro conocimiento de la sociedad y de la historia, sino también para el que nos hacemos de la naturaleza. Lo que sabemos sobre la estratosfera se asemeja a lo que sabía Platón de la Atlántida: nos lo han contado. $\mathrm{O}$, como expresa Horacio: "Eso he oído, y en parte lo creo". (Niklas Luhmann, 1996, p. 9)

\section{Introducción}

En un sentido elemental, la educación es el medio para alcanzar los fines que cada sociedad se traza como deseables, al atender las necesidades de formación del individuo y de reproducción de la sociedad. Tales fines varían históricamente, y así también se modifica la comprensión de la relación entre el individuo y la colectividad en la que se educa. A pesar de las discusiones que, hoy como ayer, surgen entre la necesidad de la formación espiritual y las demandas de lo práctico, quizá podríamos convenir en que las grandes aspiraciones de la educación en la actualidad quedan plasmadas en los componentes de la formación [Bildung] que sintetiza el filósofo Peter Bieri (2005): orientación en el mundo, cultivo de la sensibilización moral, ampliación de la capacidad de expresión, desarrollo de la autoconocimiento, la autodeterminación y la conciencia histórica.

Además de ser un medio en el sentido descrito, la educación es también un proceso mediatizado: ella necesita de medios de comunicación, desde los naturales que hacen posible el habla, y los técnicos manuales que posibilitan la escritura; hasta los dispositivos telemáticos que permiten hoy la integración de la palabra oral y escrita, el sonido y la imagen, la reproducción de lo real y la simulación virtual. Pero más allá del empleo de tecnologías, la educación está mediatizada en otro sentido. Si, como afirma Kemmis (2014), la educación es "el proceso mediante el cual niños, jóvenes y adultos se inician en modos de comprender, de actuar y de relacionarse unos con otros y con el mundo que les rodea" (p. 26), tendríamos que atender a la condición mediatizada de esa relación del sujeto con su mundo natural y social, condición que afecta incluso la manera como se conciben los sujetos, pues no es la misma idea que tienen de sí el lector del siglo XIX, el radioescucha de la primera mitad del siglo XX, el televidente de la segunda y el participante en redes sociales virtuales de comienzos del siglo XXI.

Usualmente se considera que estos temas son asunto de las facultades de comunicación y periodismo, de publicidad o de sociología. Aquí queremos sostener que, dada la importancia que adquieren tanto los medios masivos tradicionales, como los interactivos en la construcción y comprensión de nuestra realidad, ellos deben ser preocupación explícita del sistema educativo, no solo para lograr hacerlos "útiles" en la enseñanza, sino para problematizar sus significaciones políticas, culturales y sociales.

Si formarse espiritualmente es "aprender a orientarse en el mundo", un mundo que claramente trasciende en su extensión y complejidad las posibilidades de nuestra experiencia directa, entonces los recursos a través de los cuales adquirimos las imágenes de este, y los modos en que aceptamos o cuestionamos su veracidad y adoptamos o rechazamos los sentidos que nos ofrecen; son objeto legítimo de reflexión educativa.

Como sabemos, desde la antigüedad hasta la aparición de los medios electrónicos la relación de la educación con los medios ha sido de tensiones, porque cada innovación tecnológica se ha visto en su momento como una amenaza al control de las élites culturales sobre la producción, difusión, acceso e interpretación de informaciones, sobre las que fundamentan ellas su poder simbólico (Thompson, 1998; García-Leguizamón, 2010). En nuestra era, esa amenaza de "decadencia cultural" la encarnaron por mucho tiempo los medios audiovisuales, especialmente la televisión, que desafiaba la hegemonía de la cultura tipográfica. Después de años de condenarlos, y a veces con más resignación que convicción, la escuela ha ido aceptando la omnipresencia de los medios electrónicos como una realidad que no se puede desterrar de la vida escolar, pues quiérase o no, irrumpe cotidianamente en ella, no solo en la tangibilidad de sus dispositivos, sino en la in- 
tangibilidad de las comprensiones del mundo que promueve.

Ahora bien, más allá del rechazo o la indiferencia hacia los medios electrónicos, de los "pactos de convivencia pacífica” establecidos tácitamente con ellos, o de los intentos de hacerlos "útiles" en los procesos de enseñanza y aprendizaje, existe un campo educativo que se ha ocupado de estudiarlos, menos con el propósito de proteger al sujeto "indefenso" de sus influencias "funestas", que de promover el cultivo de las capacidades necesarias para orientarse inteligentemente en un mundo mediatizado, y actuar en él autónomamente. Con este propósito en mente, se han elaborado en este campo conceptos específicos de literacy y de competencia mediática, que quieren estar a la altura de las demandas sociales de formación y de las necesidades de sujetos a lo que se considera capaces de hacerse una idea de la función y el funcionamiento del sistema de los media, de pensar críticamente sobre sus propios consumos y de emplear medios de manera autónoma y responsable para sus propósitos, de acuerdo con sus interpretaciones del mundo y sus identidades personales y colectivas.

Sin desconocer las particularidades regionales y nacionales, consideramos que estas expectativas de formación expresan un deseo de las sociedades democráticas contemporáneas, interconectadas globalmente, por lo que la promoción de una educación en medios parecería no requerir de justificaciones adicionales. Sin embargo, antes que proponer en nuestros países la pronta adopción de un corpus teórico elaborado en otras latitudes, nos parece más fructífero mostrar su pertinencia partiendo de algunas interrogantes que el mundo mediatizado le plantea a la educación escolar, y observando cómo ellos son percibidos y atendidos en la formulación de horizontes normativos para los diseños curriculares. Concretamente, nos ocuparemos de un sistema educativo que recientemente ha buscado renovarse en todos sus niveles, a la luz de una reflexión actualizada sobre las necesidades presentes de formación: el de la República Dominicana.

En este sentido, trataremos inicialmente de desarrollar lo esbozado, dialogando con el documento del Ministerio de Educación de la República Dominicana (MINERD): Bases de la Revisión y Actualización
Curricular (2016), fruto de un amplio trabajo colectivo académico, que recoge las instrucciones de diferentes políticas educativas y del Pacto Nacional para la Reforma Educativa 2014-2030, lo que nos permitirá preguntarnos hasta dónde las competencias que en él se describen dan cuenta de las problemáticas de una sociedad mediatizada.

Puesto que las cuestiones implicadas no solo conciernen al sistema educativo, nos apoyamos posteriormente en un reciente estudio de la UNESCO (2017) para describir la situación actual del sistema de los medios en la República Dominicana. Luego de este recorrido, explicitaremos finalmente los conceptos de media literacy y competencia mediática, y propondremos algunos puntos que inviten a la comunidad educativa a llevar estas reflexiones a su práctica cotidiana.

\section{Los horizontes de la reforma curricular en la República Dominicana}

La Estrategia Nacional de Desarrollo para la República Dominicana, convertida en Ley orgánica a partir del 2010, se formula en torno a cuatro objetivos: 1) Un Estado democrático Social de Derecho; 2) Una sociedad con igualdad de derechos y oportunidades: 3) Una economía sostenible, integradora y competitiva; 4) Una sociedad con producción y consumo ambientalmente sostenibles que se adapta al cambio climático. El documento Bases de la Revisión y Actualización Curricular (MINERD, 2016) reconoce que el logro de estos propósitos presenta un desafío al Sistema Educativo Dominicano y formula correspondientemente la misión de la educación escolar en términos de "promover la ciudadanía, el respeto a la diversidad y la inclusión como ejes para una cultura de paz, en el horizonte de una vida digna para toda la población" (p. 35). Con ello afirma el papel específico de la educación frente a otros sistemas sociales (economía, administración) como espacio en el que se busca armonizar proyectos individuales y societales en el marco de una racionalidad ética: formar a los sujetos para la vida en una comunidad política, en que la libertad para alcanzar fines propios no da la espalda a los vínculos solidarios, esto es, a la 
preocupación por las condiciones que puedan limitar la libertad de los demás y de las generaciones futuras.

El documento del MINERD presenta algunas cifras sobre los jóvenes del país. Se registra que el 49\% de la población dominicana tiene menos de 25 años y que, según cifras del 2011, la cantidad de jóvenes entre 15 y 24 años que no estudiaba ni trabajaba alcanzó el 20,3\%. Igualmente, se describe allí una serie de problemáticas sociales (desempleo, pobreza, violencia), que representan demandas al sector educativo en términos de accesibilidad, calidad y equidad como condición de realización de los derechos consagrados en la Constitución de 2010.

El acceso generalizado al sistema educativo, la formación y actualización del magisterio y el mejoramiento de las condiciones en las que los docentes realizan su labor, son sin duda metas urgentes que reclaman una concentración de esfuerzos. Pero a medida que se avance en el camino seguramente se irán haciendo más visibles otras problemáticas que ponen en evidencia la complejidad del fenómeno educativo. Basta con recordar el hecho de que, aun ampliando la jornada escolar, la escolarización no abarca la totalidad de los procesos educativos, pues estos transcurren simultáneamente en diversos escenarios en los que se construyen nociones de mundo, no siempre coincidentes en forma y contenido con las que se promueven en la escuela.

Uno de esos escenarios lo constituyen los medios de comunicación. El documento del Ministerio hace algunas menciones al respecto, aunque de manera más bien general. Señala que "el crecimiento masivo de los medios de comunicación y las tecnologías de la información han hecho posible una mundialización de cierta cultura juvenil mediática" (p. 31), y agrega que las TIC tienen "un potencial transformador cuando es aprovechado para la información y la formación de la población" (p. 32). Describe dichas tecnologías como "herramientas que agilizan los procesos comunicativos y permiten nuevas y diversas formas de interacción", herramientas cuya efectividad depende de "la habilidad para seleccionar las más apropiadas en función del contexto y los propósitos" (p. 73). Recomienda "integrar al aula materiales impresos, manipulativos, recursos del contexto natural y sociocultural, audiovisuales, audios, interactivos y otros recursos tecnológicos [y los que] el profesorado y el estudiantado puedan crear aprovechando los materiales de su realidad" (p. 57). Pero el documento reconoce que "las manifestaciones locales de los fenómenos que se desprenden de la realidad de las nuevas tecnologías apenas han sido analizadas en nuestro país" (p. 32).

El entusiasmo frente a la disponibilidad de nuevas herramientas no elimina la natural incertidumbre frente a las implicaciones de sus usos. ¿A quién le correspondería analizarlas? Sostendremos aquí que la escuela que asume la misión de formar para la acción significativa en un mundo en transformación, no solo tiene la responsabilidad de reflexionar sobre las consecuencias sociales, culturales y políticas de los fenómenos tecnocomunicativos, sino que además es un lugar privilegiado para hacerlo.

Algunas anotaciones a los rasgos del "perfil del egresado del currículo dominicano" descritos en el documento del MINERD (pp. 61-62), nos permiten ilustrar esta afirmación al considerar explícitamente el entorno mediático en el que ellos tendrían que realizarse, una cuestión que no queda suficientemente saldada con el escueto enunciado de que el estudiante "Valora y utiliza eficazmente las tecnologías para aprender y resolver problemas" (p. 62). En la construcción de un "proyecto de vida" juegan un papel importante los modelos promocionados por las industrias mediáticas; para la definición de "metas comunes" es necesario hacerse una idea de las comunidades locales y globales a las que niños y jóvenes se vinculan simbólicamente a través de tecnologías. La formación para la "convivencia democrática” y el "respeto por la diversidad" pasa por la identificación de la imagen del otro, del "diferente", difundida en los medios masivos y en las redes sociales.

Igualmente podríamos afirmar que la posibilidad de construir una "conciencia histórica" no es independiente de la noción de tiempo existencial, de la relación entre el presente inmediato y el futuro, que se fomenta en los consumos culturales; la construcción de un ethos de "responsabilidad y solidaridad" presupone la evaluación crítica de la representación mediática de lo público y del bien común. Asimismo, 
la comunicación de "sentimientos e ideas de manera eficaz en la lengua materna” tendría que considerar las novedosas hibridaciones entre lenguajes verbales e icónicos que llenan hoy la comunicación virtual cotidiana; etc.

Los ideales de la renovación curricular se articulan con la práctica a través de un conjunto de competencias que definen el "dominio efectivo de las habilidades que una determinada sociedad acuerde como necesarias para afrontar los problemas y aportar soluciones" (p. 42). Las competencias representan "capacidades para actuar de manera autónoma en contextos y situaciones diversas, movilizando de manera integrada conceptos, procedimientos, actitudes y valores" (p. 40). El MINERD considera siete competencias específicas: ética y ciudadana; comunicativa; de pensamiento lógico, creativo y crítico; de resolución de problemas; científica y tecnológica; ambiental y de salud; de desarrollo personal y espiritual. Con más detenimiento queremos hacer algunas glosas a las competencias fundamentales descritas en el documento.

En el caso de la competencia ética y ciudadana, señalamos inicialmente que la "vivencia de una cultura democrática" y del valor social del pensamiento crítico se apoya en la percepción de intercambios comunicativos entre personajes públicos, cuando ellos están más orientados por la civilidad y la intención argumentativa que por la descalificación y el ataque personal. La voluntad de "participación” no es ajena a la manera como se definan públicamente la corrupción y la impunidad, pues no es lo mismo presentarlas como problemas a afrontar con voluntad política, control ciudadano e independencia de poderes, que como un destino inevitable frente al que cada uno tiene que aprender a arreglárselas como pueda. Así mismo, la adopción del principio de "igual reconocimiento" no es indiferente a la manera como se escenifiquen mediáticamente los roles de género, se difundan discursos de odio o se reproduzcan veladamente estereotipos de minorías.

En lo que respecta a los roles de género, el Plan Nacional de Igualdad y Equidad de Género 2007-2017 (Ministerio de la Mujer, 2011), ha descrito con precisión el problema que aquí señalamos:
Los medios de comunicación reflejan, más que otras áreas sociales, la cultura de la desigualdad entre mujeres y hombres. Estando fundamentalmente en manos masculinas y privadas, se hacen eco de las imágenes y las informaciones que más venden, es decir, las que potencian el poder tradicional masculino y trivializan a las mujeres. Los estudios realizados en países de diferentes culturas arrojan que las mujeres no sólo están sub-representadas en los medios de comunicación, sino que además están mal representadas. Por otra parte, con frecuencia las imágenes femeninas que nos transmiten son desfasadas y no están acordes con los nuevos roles que las mujeres han asumido en la sociedad de hoy (p. 37).

La escuela y los medios son espacios fundamentales de reproducción cultural y el Plan llama a trabajar en ambos para modificar las representaciones sobre la mujer. En la escuela, rompiendo patrones de clasificación y de comportamiento que reproducirán en adelante la desigualdad; en los medios, introduciendo una comunicación con perspectiva de género, rechazando la publicidad sexista, visibilizando los aportes de las mujeres a la cultura y a la ciencia, y comprometiendo a los creadores de cultura popular a darle a las mujeres un lugar digno en sus producciones. Pero más allá de los trabajos de sensibilización, es necesario transformar las estructuras del sistema: "Para penetrar en ese mundo de la comunicación, hasta ahora un tanto ajeno y también hostil, hay que formar mujeres profesionales que puedan ocupar puestos clave en la producción y dirección de medios escritos y audiovisuales" (Ministerio de la Mujer, 2011, p. 38). Podríamos todavía preguntarnos si estos propósitos no tendrían que apropiarse también en la escuela, fomentando no solo la crítica sino también la producción de contenidos mediáticos con enfoque de género.

El documento del MINERD relaciona también esta competencia ética y ciudadana con la capacidad de "identificar las intenciones en los mensajes publicitarios y los que circulan en las redes" (p. 27). En este sentido, lo que acabamos de señalar con respecto al género podría complementarse en relación con la 
política, refiriéndonos por ejemplo al fenómeno de la "mediatización de la política", en el cual mutan las relaciones entre estos dos sistemas, hasta el punto de que la política se somete a los lenguajes y formatos mediáticos, con la visible consecuencia de que la comunicación política resulta ocupándose menos de la exposición y discusión de ideas y programas, que del manejo de imagen y el posicionamiento de productos, estrategias propias del marketing.

La disposición de "aportar sugerencias para construir normas justas, así como la posibilidad de sensibilizarnos ante las situaciones de injusticia social" ( $\mathrm{p}$. 69) y de reconocer prácticas de exclusión, mencionadas por el documento del Ministerio, dependen, en buena medida, de la existencia o inexistencia de narrativas audiovisuales y escritas que tematicen el absurdo de la crueldad que hay en toda exclusión, estimulen nuestra imaginación moral y fomenten el desarrollo de la empatía. Ahora bien, estas narrativas no solo son relatos de ficción, sino también de nuestra historia remota y reciente; tener conciencia de ella (conciencia histórica) y poder entendernos como momento de un devenir, tejido en buena medida con nuestras acciones y que se tiende entre lo que hemos sido y lo que aspiramos a ser, supone soportes estables y confiables de memoria.

Hace tres décadas el comunicólogo Vilem Flusser (1989) saludaba el arribo de las memorias electrónicas como algo que contribuiría a liberar a los seres humanos, no solo de la carga de tener que almacenar informaciones, sino también de su relación "sacralizada" con la biblioteca como memoria cultural. En adelante, sería menos importante aprender los datos que cultivar una nueva forma de tratar con ellos, algo que llamaría más al juego creativo que a la obediente repetición.

Hoy sabemos que la inmediata disposición de informaciones en internet nos ha liberado de la farragosa memorización enciclopédica -lo que sin duda ha tenido efectos renovadores en la educación- pero que al mismo tiempo parece desestimular la memorización que hace posibles los aprendizajes sociales. Un flujo ininterrumpido de informaciones absorbe de manera fugaz, desordenada y fragmentaria nuestros limitados recursos de atención, sin dejar tiempo a la reflexión y a una mirada ponderada del conjunto. Como nos recuerda Boris Schumatsky (2016), el ritmo más o menos pausado de difusión informativa en tiempos del dominio de los medios masivos, con sus pocos canales electrónicos y sus imprentas, evitaba que el error noticioso llegara a los libros de historia. Pero en tiempos de la red, cualquier mentira puede crear inmediatamente una realidad: el medio internet produce su propia relación con la verdad.

Por otro lado, la competencia comunicativa es definida por el MINERD como la "capacidad de expresar y comunicar mensajes empleando formas y estructuras lingüísticas diversas conjuntamente con otras manifestaciones de la comunicación, como son la comunicación corporal, la icónica, la digital, etc.” (p. 71). Esta capacidad "supone la adaptación de la comunicación a las distintas audiencias y situaciones, así como la evaluación constante de la efectividad de los modos, medios y estrategias utilizados en la comunicación” (p. 73). Pero no se limita al acopio de destrezas para la persuasión o las relaciones públicas, sino que se le asigna un rol deliberativo democrático, en tanto se considera que ella contribuye al "fortalecimiento y la estabilidad de las sociedades democráticas, pues posibilita la expresión del pensamiento convergente y divergente, así como la construcción de acuerdos, [y que] contribuye además a la toma de conciencia con respecto a los distintos mecanismos que en la comunicación se utilizan para la manipulación y el ejercicio del poder" (p. 71). Al formularse de esta manera, se le asigna un lugar central en la producción de emisiones públicas.

Ahora bien, sabemos que en el mundo real no todas esas emisiones compiten en igualdad de condiciones, por lo que es necesario situar el ejercicio de la competencia comunicativa en el contexto de la disputa por la constitución de un espacio público de comunicaciones, en el que tengan cabida diferentes voces y formas de expresión, algo que en nuestros países se suele ver distorsionado por la injerencia en los medios masivos de intereses particulares respaldados por formas de poder económico, social o político.

Esta situación abre algunos interrogantes sobre el funcionamiento del sistema de la comunicación pública, que es importante plantear desde la escuela. En 
primer lugar, interrogantes sobre si se provee al ciudadano de información suficiente, veraz y oportuna para que se haga una idea acertada sobre lo que es relevante para todos en un momento determinado: ¿Quién y con qué criterios define y organiza lo que se le presenta a la sociedad como importante? ¿Qué relación existe entre la agenda de los medios, la de los públicos y la de los políticos? ¿Incide la forma en que se presenta una noticia en la interpretación que le damos? ¿Qué efectos genera en el público una opinión que se presenta como mayoritariamente aceptada? ¿Cuál es el límite entre el cubrimiento de un suceso y el sensacionalismo? ¿Cuál es la diferencia entre un escándalo "real” y uno mediático? ¿Se puede aprender socialmente de los escándalos sin caer con ellos en pánicos morales o en el señalamiento de chivos expiatorios? ¿Qué límites debe tener la revelación de lo privado y lo íntimo?

En segundo lugar, está el problema de la participación. Vivimos hoy en una "sociedad de la redacción generalizada”, en la que cada uno se convierte fácilmente en productor público de información. En este contexto, señala Bernhard Poerksen (2018), los principios ideales del periodismo dejan de ser algo que atañe exclusivamente a los periodistas profesionales y pasan a ser parte fundamental de la cultura general de los ciudadanos. Para cada uno valen las exigencias de verificar lo que publica, analizar fuentes, esforzarse por abandonar la burbuja de los propios prejuicios, mantenerse escéptico frente a las ideologías de todo tipo, identificar las estrategias de los relacionistas públicos, escuchar el otro lado de las historias, abrirse a contraargumentaciones, contribuir a develar escándalos reales y respetar la presunción de inocencia. De aquí se deducen para todo "prosumidor" dos imperativos fundamentales: darle al público toda posibilidad de enjuiciar las informaciones que le transmito; nunca concebir la propia comunicación como un punto final, sino siempre como comienzo e impulso para el diálogo.

Esto último nos anticipa un escenario para la realización de la competencia de pensamiento lógico, creativo y crítico. El pensamiento crítico, nos dice el documento del MINERD, "permite cuestionar los fundamentos de las ideas propias y ajenas. Su ejerci- cio exige analizar la veracidad de las informaciones en las que se basan las opiniones y juicios y comparar diversos puntos de vista, considerando los intereses de las distintas personas que actúan y los contextos a los que pertenecen, [lo que contribuye] a superar prejuicios y estereotipos y a centrarse en el examen de la validez de las ideas y opiniones" (p. 78).

Pero la realización de esta aspiración no es indiferente a las condiciones mediáticas de las sociedades contemporáneas y los patrones de sociabilidad que promueven. Como se ha señalado en los últimos años (Pariser, 2017), las redes sociales virtuales no están necesariamente programadas para abrirse al contacto con lo diferente y relativizar el propio punto de vista, sino más bien para reproducir lo semejante y generar la cómoda percepción de un mundo uniforme.

Los algoritmos selectivos de redes como Facebook no favorecen la desnaturalización espontánea de las visiones homogéneas, sino que naturalizan un consenso en torno a visiones afines que se toman por la realidad en sí. Pero no es solo un problema técnico. Frente al ideal de una apertura de los sujetos hacia un cosmopolitismo, hacia una autocomprensión como ciudadanos del mundo, lo que viene presentándose en los últimos años es una afirmación de neotribalistas, formas particulares de redefinición del "nosotros" con problemáticas consecuencias para la democracia que se pueden apreciar en el avance de los neopopulismos de derecha, en varias partes del mundo (Geiselberger, 2017; Fukuyama, 2018).

La polarización vincula además fenómenos lingüísticos con mecanismos cognitivos de selección informativa, que se activan para confirmar creencias preestablecidas y rechazar toda evidencia que las desafíe. En un momento en que existe la posibilidad de explotar para fines políticos o comerciales la microperfilación que realizan expertos a partir de las huellas que dejamos en nuestra "vida digital", como mostró el escándalo de Cambridge Analytica, saber cómo operan tales mecanismos técnicos y cognitivos no debe ser de menos interés para los educadores, de lo que lo es para publicistas y propagandistas.

Algunas observaciones caben también en relación con la competencia ambiental y de la salud. Según el documento del MINERD, "la escuela es el espacio 
idóneo para educar a favor de la salud sexual y reproductiva, así como de una sexualidad responsable tanto en los hombres como en las mujeres" (p. 94). Allí se identifica además la necesidad de "enfrentar las consecuencias del consumo de alimentos de bajo contenido nutricional y con aditivos, el uso y abuso de drogas, alcohol, tabaco y otras sustancias dañinas al cuerpo, embarazos no deseados (...); y se propone "desarrollar hábitos saludables en la vida cotidiana, identificar factores desequilibrantes y promover el conocimiento y valoración del mismo cuerpo" (p. 94).

De nuevo, el logro de estas metas presupone el análisis de los hábitos de consumo que promueve la publicidad comercial, de sus trucos en la administración del deseo y de los imaginarios que de él se producen desde la edad temprana. Pero hay en todo esto un aspecto que queremos poner de relieve, y que es fundamental en la formación niños y jóvenes.

En una obra ya clásica, sostenía Neil Postman (1988) que la televisión abrió las puertas del mundo de los adultos a los niños, de manera que estos podían acceder, vía entretenimiento, publicidad y noticias, a lo que el mundo del libro había logrado mantenerles oculto: la sexualidad. Entre tanto, hemos pasado de las meras insinuaciones y ambigüedades eróticas televisivas de aquella época, a una abundancia de ofertas de sexo explícito en internet poco susceptibles de ser controladas. Las cifras son suficientemente dicientes: uno de los sitios más populares, Pornhub, tuvo en 2017 más de 28,500 millones de visitas, esto es, 81 millones al día y 56,000 por minuto (Castleman, 2018). Como señala un estudio reciente publicado en el New York Times (2018), para los jóvenes, hoy, la primera fuente de aprendizaje sobre sexo no son las clases, ni los libros, ni los amigos ni los padres, sino la pornografía en línea, que se empieza a consumir antes de los 15 años. Es allí donde se construye una parte considerable de las representaciones sobre el propio cuerpo, la intimidad, el placer y la forma de relacionarse con el sexo opuesto (por ejemplo, la creencia de que a las mujeres les gusta ser tratadas con agresividad), un conjunto de estereotipos que generan ansiedad, inseguridad y frustración.

Agrega el mismo estudio, que a pesar de que se les permiten a los adolescentes los teléfonos inteligentes, "la educación sexual en los colegios basada en la abstinencia sigue siendo la norma”. Concluye entonces que, más que prohibir estos consumos, algo que resulta hoy prácticamente imposible, sería más conveniente generar una mirada crítica sobre ellos, una "porno alfabetización" (porn literacy), que permita abordar abiertamente estos temas de manera que se aprenda a diferenciar lo falso de lo real.

Ahora bien, más allá de las diferencias culturales que puedan existir entre los jóvenes norteamericanos y los caribeños, lo cierto es que los sitios de pornografía gratuita están igualmente disponibles para cualquier adolescente en el mundo que porte en su bolsillo su terminal privada de conexión a la red. Según datos de la UNESCO (2017), el $71 \%$ de los jóvenes dominicanos entre los 12 y los 14 años, y el $80 \%$ de los que están entre los 15 y los 19 años usan la internet regularmente. Una educación que se preocupe por brindar una equilibrada orientación sexual no puede desentenderse de estos fenómenos mediáticos.

Lo dicho con relación a la sexualidad vale también para la última competencia descrita en el documento del MINERD, la de desarrollo personal y espiritual, si consideramos que ella se refiere a la manera como "la persona se descubre y acepta a sí misma: su cuerpo, sus talentos, sus fortalezas, limitaciones, emociones y sentimientos; logra regularlos y trabaja de forma consciente en la construcción de una equilibrada percepción de sí misma, a través de una interrelación constructiva con los y las demás. Esta competencia capacita al o a la estudiante para el reconocimiento de la dignidad propia y la de todas las personas, del respeto y valoración de las diferencias y la diversidad" (p. 100). Señalaremos brevemente que el reconocimiento de lo diferente corre paralelo con los procesos de construcción de la propia identidad, individual o social, y de las narrativas que de ella van surgiendo en una constante interacción de experiencias y modelos puestos en escena mediáticamente.

\section{La situación de los medios masivos en la República Dominicana}

Las tecnologías interactivas han transformado el entorno mediático desplazando a los medios masi- 
vos tradicionales del centro que ocupaban, pero sin relevarlos completamente de sus funciones. Ellos siguen siendo decisivos al definir agendas públicas y al concentrar en un momento determinado la atención de toda una nación en un tema, constituyendo una esfera pública amplia, condición básica del funcionamiento de una sociedad democrática. De manera que al reflexionar sobre los medios desde la educación y sobre los fines de la educación en el contexto de una sociedad mediatizada, resulta pertinente detenernos por un momento en un diagnóstico de ese segundo subsistema implicado. Para este propósito contamos con un estudio reciente de la UNESCO: Análisis del desarrollo mediático en República Dominicana (2017), en el que se presenta someramente su historia, se hace un conteo de su cobertura y se bosqueja un panorama de las condiciones que posibilitan o limitan sus rendimientos democráticos en cuanto a la libertad de expresión, la apertura al pluralismo, la propiedad y las condiciones de formación profesional de quienes ejercen el periodismo. Resaltaremos algunas observaciones que a primera vista nos parecen relevantes para esta presentación.

El estudio señala que "los informativos o noticiarios radiofónicos prácticamente desaparecieron de la radio nacional, que es cada vez más interactiva" (p. 20). Y aunque se advierte una segmentación de audiencias producto de la diversidad de ofertas, se observa que "las emisoras de mayor audiencia son aquellas que tienen mayores programas interactivos, en los que la audiencia participa mediante la vía telefónica” (p. 20); algo que, puntualizamos nosotros, ofrecería un rico campo de observación sobre los temas y los modos de intercambio comunicativo a través de los cuales se constituye propiamente una esfera pública popular, más allá de los editoriales de la prensa escrita.

El marco jurídico que rige el sistema dominicano, se le describe como "deficiente e insuficiente", en cuanto que se presentan todavía contradicciones normativas en la defensa de libertades básicas. Así mismo se percibe una ausencia de mecanismos de monitoreo y control por parte de la sociedad civil para exigir que las instituciones mediáticas cumplan con su compromiso de construir una ciudadanía demo- crática. En un panorama en el que predominan los medios privados (solo el $2 \%$ es estatal o religioso), es preocupante el hecho de que no haya una regulación sobre el oligopolio en la propiedad mediática, lo que de una parte genera en las audiencias una falsa imagen de pluralismo y de otra oculta las relaciones de las empresas mediáticas con otros sectores de la economía, permitiendo que pueda presentarse como información, lo que son contenidos publicitarios. Igualmente, problemática resulta la combinación de formas de poder que surge de los vínculos entre dirigentes políticos y medios.

Frente al poder de empresas privadas se constata un limitado alcance y una débil influencia de los medios estatales. Mientras que en todas las regiones del país hay una notoria presencia de medios electrónicos religiosos no comerciales (católicos y protestantes), hay ausencia de medios comunitarios, debido no solo al poco impulso estatal para su conformación, sino también a la inexistencia de movimientos sociales que demanden una mayor participación civil en la comunicación pública.

Un valor fundamental de los medios masivos en una democracia es su credibilidad, esto es, la confianza de la ciudadanía en que ellos cumplan con sus funciones. Lo que en tal sentido se espera de los medios masivos, lo han sintetizado Gurevitch y Blumler (1990) en un texto que mantiene su vigencia: la vigilancia del entorno sociopolítico reportando innovaciones que probablemente inciden positiva o negativamente en el bienestar de los ciudadanos; el establecimiento de una agenda en la que se identifiquen las problemáticas esenciales del momento y las fuerzas que les han dado forma y podrían resolverlas; el ofrecimiento de plataformas en las que tanto políticos como voceros de diversas causas y grupos de interés puedan presentar sus puntos de vista de manera inteligible e ilustrativa; que posibiliten el diálogo entre quienes detentan el poder y los públicos; que activen mecanismos para el rendimiento de cuentas de quienes ocupan cargos públicos; que incentiven a los ciudadanos a aprender y a que se involucren en procesos políticos, en vez de limitarse a mirarlos desde la distancia; que ejerzan, con base en principios, resistencia frente a las fuerzas externas que puedan 
minar su independencia, su integridad y su capacidad de servir a las audiencias; que promuevan un sentido de respeto por los miembros de la audiencia como sujetos que pueden potencialmente interesarse en su entorno político y entenderlo.

Ahora bien, según al estudio de la UNESCO, existe una marcada percepción en la población dominicana de que los medios se alejan de sus funciones democráticas y apenas el 46,3\% de la población dice confiar en ellos. Aunque el $81,9 \%$ considera que los medios todavía canalizan denuncias y reclamos de diversos sectores sociales, y el $54,7 \%$ cree que contribuyen a la resolución democrática de conflictos sociales, económicos y políticos, solo el 49,6\% considera que cumplen con su función de vigilancia de los poderes públicos. De nuevo, aunque el $57,7 \%$ percibe una apertura hacia las denuncias de los ciudadanos para prevenir y castigar actos de corrupción de funcionarios, el $78 \%$ cree que los medios no responden a los intereses de sus audiencias.

El cuestionamiento ético es alto. El 60\% de encuestados duda de la independencia del periodismo frente a los poderes políticos, económicos y religiosos, y el $70 \%$ considera que el ejercicio del periodismo no está libre de corrupción. Al entrevistar periodistas, se encuentra que no perciben incoherencia ética en prácticas que universalmente se consideran contrarias al periodismo de calidad (regalos privados, empleo de lenguaje de odio, sensacionalismo, combinación de política y periodismo, etc.). El estudio concluye también que hay muy pocos mecanismos de autorregulación, que solo un diario tiene un código de ética y que el del Colegio Dominicano de Periodistas no se aplica.

A partir de este diagnóstico, la UNESCO hace una serie de recomendaciones al Estado para que proteja la libre expresión y el derecho de los ciudadanos a recibir información suficiente e imparcial sobre los que les afecte. Así mismo, para que frene el proceso oligopólico y vigile que el interés comercial no se ponga por encima de la misión democrática de los medios. Otras recomendaciones tienen un carácter educativo: se llama a "las organizaciones mediáticas, a las universidades e instituciones estatales relacionadas con la comunicación a propiciar la democratiza- ción, el ejercicio ético y el pluralismo de los medios, creando observatorios y capacitando a la población sobre sus derechos mediáticos" (p. 29).

Por lo que hemos dicho hasta ahora, resulta claro que estas recomendaciones deben encontrar eco también en la escuela. Aunque el informe parece pasar esto por alto, sí reconoce que el viejo sistema de los medios está asediado hoy por "usuarios de redes sociales [que] ya no son solo lectores-oyentes-teleespectadores inertes, [sino que] escriben, hablan, fotografían, filman, comentan, analizan”, y que "en la nueva sociedad de redes, cada ciudadano es un periodista en potencia" (p. 59). Formar estos "prosumidores" conscientes, capaces de cuestionar novedosamente las construcciones de realidad de los medios masivos y de llamarlos a cumplir con sus tareas democráticas, es legítimamente una misión de la escuela.

\section{Conclusiones y recomendaciones}

Luego de este recorrido, si le pidiéramos al lector hacer un listado de las capacidades y habilidades que considera que debería promover un proyecto de educación mediática aplicable a su contexto, esta encontraría seguramente coincidencias importantes con las que contempla la educación o pedagogía de medios en aquellos lugares donde ha logrado consolidar una tradición: crítica, conocimientos específicos y uso creativo. Para mencionar dos ejemplos, en el mundo anglosajón se entiende la "alfabetización" mediática (media literacy), como la capacidad de acceder, comprender y crear comunicaciones en una variedad de contextos. El acceso hace referencia a las destrezas necesarias para ubicar informaciones sirviéndose de las tecnologías disponibles; comprender significa aquí la capacidad de descodificar e interpretar mensajes mediáticos (a través del dominio de sus convenciones, las características de sus diseños y sus recursos retóricos), pero también implica un conocimiento de los procesos de producción, los modelos de propiedad, las formas de control institucional, así como la capacidad de criticar los medios, por ejemplo, en términos de su confiabilidad y de sus representaciones del mundo. Crear se refiere a la capacidad de servirse de 
medios para producir y comunicar mensajes propios, ya sea con propósitos de autoexpresión o con el fin de interactuar con otros (Buckingham, 2007). Dimensiones similares: conocimiento de los sistemas, análisis, crítica y producción creativa, hacen parte del concepto alemán de competencia mediática [medienkompetenz], entendida como la capacidad de usar los medios y sus contenidos de manera bien informada y acorde con los propios propósitos e intereses (Baacke, 1997).

De aceptarse la legitimidad de las preocupaciones aquí expuestas, podríamos preguntarnos si para darles acogida en el diseño curricular basta con interrogar en clave mediática las diferentes competencias que adopta el MINERD; si es suficiente con ampliar la descripción del contexto sociotécnico en que debe desplegarse la competencia comunicativa; o si la especificidad de las problemáticas bosquejadas demandaría la formulación explícita de una competencia mediática. Por encima de esta disyuntiva está, sin embargo, un propósito más importante de estas reflexiones: señalar la urgencia de que el sistema educativo amplíe su noción de lo mediático más allá de la condición de herramienta en los procesos de enseñanza y aprendizaje, para comprenderlo como un elemento constitutivo de lo que somos individual y colectivamente. Tal es el sentido que ha querido captar la noción de una ecología de medios: que las transformaciones mediáticas no representan solo adiciones o substracciones que afectan parcial y aisladamente sectores de nuestra vida (Poersken, 2016), sino que modifican el conjunto de nuestras relaciones, la forma de comprendernos y narrarnos a nosotros mismos, nuestra percepción del tiempo y el espacio, nuestro mundo profesional, nuestras representaciones y acciones políticas.

$\mathrm{Si}$, como señalamos al inicio, educarse es aprender a orientarse en el mundo, un mundo mediatizado demanda con apremio una educación en medios. A través de una serie de glosas al documento ministerial de renovación curricular en la República Dominicana, esbozamos algunas de las muchas cuestiones que a primera vista emergen en este campo. De haber logrado con ello suscitar interés y curiosidad sobre esta perspectiva de análisis, correspondería ahora a los educadores llevar más allá estas ideas generales para identificar temáticas relevantes en sus propios contextos, y explorar maneras de abordarlos en su práctica cotidiana. Por ejemplo, y a manera de sugerencia, podríamos mencionar pequeños proyectos sobre análisis crítico de los contenidos y los lenguajes de los programas de mayor rating en radio y televisión; exploración de los mundos que construyen y habitan los jóvenes en las redes: ¿qué valor le dan a sus selfies? ¿A quién siguen? ¿Cómo expresan sus opiniones? Aprovechamiento de la disponibilidad tecnológica para realizar sencillas producciones que trasciendan el trabajo de aula y puedan ser divulgados a un público local, regional o global; ejercicios de construcción colectiva a través de la producción transmediática entre diferentes centros educativos; motivación al periodismo ciudadano que vincule a los jóvenes con las problemáticas de sus barrios; análisis de las intenciones y consecuencias de las noticias falsas; etc.

Cuestiones como estas no solo liberan la reflexión sobre los medios en la educación de su confinamiento en la estrecha parcela de la tecnología educativa, sino que además promueven el espíritu investigativo y propician el trabajo interdisciplinario. El campo está pues abierto y sus objetos están a disposición. Solo nos resta construir la comunidad académica que con su trabajo le asegure un lugar en la agenda educativa de la región.

\section{Referencias}

Baacke, D. (1997). Medienpädagogik. Tubinga, Alemania: Niemeyer.

Bieri, P. (2005). Wie wäre es, gebildet zu sein? Neu Zürcher Zeitung. Recuperado de https://www. nzz.ch/articleDAIPS-1.182217

Buckingham, D. (2007). Digital Media Literacies: Rethinking Media Education in the Age of the Internet. Research in Comparative and International Education, 2(1), 43-55.

Castleman, M. (2018). Surprising New Data from the World's Most Popular Porn Site. Psychology Today. Recuperado de https://www.psychologytoday.com/us/blog/all-about-sex/201803/

Ciencia y Educación 2018; 2(2): 29-40・Ensayos • 39 
surprising-new-data-the-world-s-most-popular-porn-site

Flusser, V. (1989). Gedächtnisse. En Ars electronica (Ed.) Philosophien der neuen Technologie (pp. 41-55). Berlin: Merve.

Fukuyama, F. (2018). Against Identity Politics. The New Tribalism and the Crisis of Democracy. Foreign Affairs. Recuperado de: https://www.foreignaffairs.com/articles/americas/2018-08-14/against-identity-politics

García-Leguizamón, F. (2010). Educación en medios ayer y hoy: tópicos, enfoques y horizontes. $\mathrm{Ma}$ gis - Revista internacional de investigación en educación, 2(4), 279-297.

Geiselberger, H. (ed. 2017). El gran retroceso. Bogotá, Colombia: Seix Barral.

Gurevitch, M. \& Blumler, J. (1990). Political Communication Systems and Democratic Values. En: J. Lichtenberg (ed.) Democracy and the Mass Media (pp. 24-35). Nueva York, E.U.A: Cambridge Univ. Press.

Jones, M. (2018). What Teenagers Are Learning From Online Porn. The New York Times. Recuperado de https://www.nytimes.com/2018/02/07/ magazine/teenagers-learning-online-porn-literacy-sex-education.html

Kemmis, S., et al. (2014). Changing Practices, Changin Education. Singapur: Springer.

Luhmann, N. (1995). Die Realität der Massenmedien. Opladen: Westdeutscher Verlag.

MINERD (2016). Bases de la Revisión y Actualización Curricular. Santo Domingo: MINERD.
Ministerio de la Mujer (2011). PLANEG II - Plan Nacional de Igualdad y Equidad de Género 2007-2017. Santo Domingo: Ministerio de la Mujer.

Pariser, E. (2017). El filtro burbuja. Cómo la web decide lo que leemos y lo que pensamos. Madrid: Taurus.

Poerksen, B. (2018). Alle müssen Journalisten sein. Die Zeit. Recuperado de https://www.zeit. de/2018/08/umgang-medien-fake-news-propaganda-journalismus

Poersken, B. (2016). Wir lernen Netz. Die Zeit. Recuperado de https://www.zeit.de/2016/09/ digitalisierung-soziale-netzwerke-ueberwachung-mediennutzung-schulfach.

Postman, N. (1988). La desaparición de la niñez. Barcelona: Círculo de Lectores.

Schumatski, B. (2016). Politik, Populismus und Lüge. Die Krise der Wahrheit. Neue Zürcher Zeitung. Recuperado de https://www.nzz.ch/meinung/ kommentare/politik-populismus-und-luege-die-krise-der-wahrheit-ld.15541

Thompson, J. (1998). Los media y la modernidad. Madrid, España: Paidós.

UNESCO (2017). Análisis del desarrollo mediático en la República Dominicana. Programa Internacional para el Desarrollo de la Comunicación. Oficina Regional de Cultura para América Latina y el Caribe. 